\title{
Obituary Alan Arthur Boulton
}

Neuropsychopharmacology (201 I) 36, 2789-2790; doi: | $0.1038 / n p p .2011 .214$

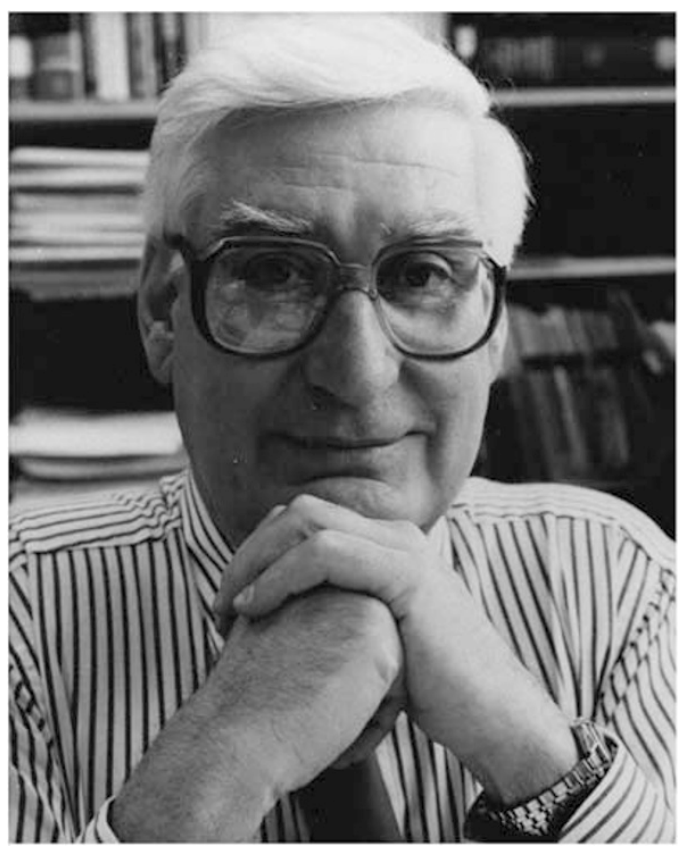

Alan Arthur Boulton died on 13 November 2010, at the age of 74, in his home in Nanaimo, Vancouver, British Columbia, where he had lived since his retirement in 2003. $\mathrm{He}$ is survived by his wife Anne, three children, seven grandchildren, and two great grandchildren. He was elected to the ACNP in 1987, and was a Fellow-Emeritus.

Born and raised in Derbyshire, England, Alan earned a PhD degree in Biochemistry in 1962 from the University of Manchester Institute of Science and Technology. He was appointed Honorary Research Fellow in the Department of Physiology, and staff member of the BMRC Unit for Research on the Chemical Pathology of Mental Disorders at the University of Birmingham, where he remained until 1968, when he accepted a research position in Canada, with the Psychiatric Research Division of the Province of Saskatchewan Department of Health in Saskatoon, with a joint appointment in the Department of Psychiatry of the Medical College of the University of Saskatchewan. He eventually served as Director of Provincial Psychiatric Research until 1987 and then served as the Director of the University's Neuropsychiatric Research Unit until his retirement. He achieved the rank of Professor in the Department of Psychiatry in 1975, and maintained an active academic career in neurochemical research until his retirement, and thereafter, continued the development of novel drugs in his company Alviva Pharmaceuticals.

Alan's overarching research interest was to elucidate and understand the roles of novel biogenic amines that might have a physiological or pathological role in the central nervous system cellular signal transduction, and later in his career, that had potential for pharmaceutical applications. He was a pioneer in quantitative research on trace amines, including 2-phenylethylamine, tyramine, octopamine, and tryptamine, and their involvement in the etiology and pharmacotherapy of psychiatric and neurologic disorders. He was recognized as a pioneer in their detection in the central nervous system, and the development of methods for their analysis. The contributions of his lab on monoamine oxidase inhibitors and their effects on levels of the trace amines led him into a search for drugs useful in the treatment of psychiatric and neurologic disease. His name is linked to the first 30, of now more than 40, volumes in the 'Neuromethods' series, which he originated and co-edited for 20 years. Recognition of his many contributions include his Fellowship in the Royal Society of Canada, and of the Canadian College of Neuropsychopharmacology, the Queen's Golden Jubilee Medal, and the Heinz Lehmann awards of the Canadian College of Neuropsychopharmacology. He was also awarded an Honorary DSc from the University of Manchester.

It would be difficult to overstate Alan's Boulton's impact on basic and clinical neuroscience research in Saskatoon. He had a talent for garnering research funds from varied sources, for bringing in new investigators and visiting scientists, and generally, for drawing national and international attention to a much-neglected geographic region. He mentored doctoral students and post-doctoral fellows who are now scattered about the Provinces of Canada and beyond.

Alan Boulton's organizational skills extended beyond his administrative roles in Saskatoon, serving as a founding member of the World Federation of Biological Psychiatry, as well as of the CCNP. He was an editorial board member of numerous journals, most notably perhaps of the Journal of Neurochemistry, for which he was the chief editor for 5 years.

With his ample height and girth, coupled with prematurely white hair, Alan looked older than his years. He stood out in a crowd, effortlessly commanding attention. Like the jury member who sits down at the head of the table, Alan seemed to gravitate toward leadership positions. It was not surprising to learn that Alan had been president of the Saskatchewan Section of the Canadian Diving Association, vice-president of the Saskatchewan Skiing Association, and treasurer of the English and Welsh Folkfest Society, nor that he was locally politically active, defending the rights of the downtrodden.

Alan was a frequently invited or elected council member or officer holder in professional societies. Neurochemists 
who attended the American Society for Neurochemistry Meeting in 1995 recall the shock of seeing Alan, their President, still with a full head of hair, but dyed jet black. He no longer bore one's preconceived image of the savvy senior statesman. Alan bravely survived the initial stares, dropped jaws, and whispered comments. The ASN members soon reassured themselves that he was still the good old Alan.

My personal acquaintance with Alan began with a conference call in 1984, from Alan and Victor Whittaker, President-elect and Secretary, respectively, of the International Society for Neurochemistry, asking me to agree to be a candidate for Treasurer in the upcoming election cycle of the Society. Income from the Journal of Neurochemistry was, and still is, the principal source of funding of the biennial ISN meetings. I soon learned that serving as Treasurer of an organization that was chartered and audited in the UK, of a journal that was at the time published in the US, with income in US dollars, and investments primarily in the US and Canada, constituted a major challenge. All this went on before the availability of fax, let alone the Internet. There were regular telephone consultations. Alan's experience and advice was invaluable during my 4 years as the ISN Treasurer and 2 years as the Chairman. I recall Council meetings in various countries (Italy, Venezuela, Portugal, Germany, Czechoslovakia, and Australia) where Alan's jovial demeanor and sense of fairness prevailed, and for that I remain in his debt.

Bernard W Agranoff
${ }^{1}$ Molecular and Behavioral Research Institute,
University of Michigan, Ann Arbor, MI, USA
E-mail: Agranoff@umich.edu

